\section{Saúde mental no enfoque das mulheres afetadas pelo Zika vírus: um estudo etnográfico no Estado do Pará, Brasil}

\author{
Mental health from the perspective of women \\ affected by the Zika virus: an ethnographic study \\ in Pará State, Brazil
}

\section{Salud mental desde el enfoque de las mujeres afectadas por el virus del Zika: un estudio etnográfico en el Estado de Pará, Brasil}

Deisiane Amorim da Silva 1

Érica Quinaglia Silva 1,2

doi: 10.1590/0102-311X00100019

\section{Resumo}

O presente trabalho traz uma reflexão sobre o surto causado pelo Zika vírus, que atingiu a população brasileira e acabou gerando consequências não somente físicas como também emocionais para todos os envolvidos. Há um grupo particular que tem de lidar todos os dias com as dificuldades dessa nova realidade imposta: as mulheres. A abordagem desse tema parte do pressuposto da necessidade de conhecer, compreender e apreender essas questões biopsicossociais em sua amplitude e magnitude. Torna-se necessário adentrar um contexto relativamente novo que atingiu principalmente mulheres negras e pardas, pobres e com baixa escolaridade, a fim de traçar melhorias na atenção aos direitos reprodutivos e à saúde mental delas. Assim, a realidade das mulheres que tiveram filhos com diagnóstico de microcefalia em virtude do Zika vírus foi acessada. Para tanto, foi realizado um estudo de abordagem qualitativa, de cunho etnográfico, em uma instituição de referência no atendimento à saúde da mulher e da criança no Estado do Pará. Verificou-se que as mulheres nessa situação não foram ouvidas ou cuidadas, além do atendimento normatizado para um pós-parto. Concluiu-se que, apesar dessa falta, a saúde mental dessas mulheres é afetada desde o início da gravidez. Logo, os contextos familiar e social tornam-se importantes para fomentar discussões sobre as práticas de saúde e as representações que o Zika acarreta para as mulheres que tiveram sua vida alterada pela situação que provocou um grande alarme em toda a sociedade.

Zika Vírus; Saúde Mental; Política Pública

\author{
Correspondência \\ D. A. Silva \\ Rua dos Milagres 5, Belém, PA 66079-460, Brasil. \\ deise0803@gmail.com \\ 1 Universidade Federal do Pará, Belém, Brasil \\ 2 Universidade de Brasília, Brasília, Brasil.
}




\section{Introdução}

Em 2015, as atenções internacionais estiveram voltadas para a saúde pública do Brasil, pois o que estava se tornando um surto nacional podia rapidamente globalizar. $\mathrm{O}$ fato que proporcionou olhares tão atentos estava relacionado à epidemia causada pelo Zika vírus (ZIKV), que até então não ganhava grande repercussão nos cenários nacional e internacional por não apresentar grande demanda ou consequências significativas para a saúde.

Nesse contexto, em fevereiro de 2016, o Comitê de Emergência da Organização Mundial da Saúde (OMS) e a Organização Pan-Americana da Saúde (OPAS) realizaram uma primeira reunião de acordo com os termos do Regulamento Sanitário Internacional (RSI, 2005), que preveem a notificação de casos que possam ser declarados como uma situação de Emergência de Saúde Pública de Importância Internacional (ESPII). Essa reunião determinou a vigilância da infecção, o desenvolvimento de pesquisas que possibilitassem o diagnóstico, medidas de vigilância e controle e o acesso à informação para a população, sobretudo para as mulheres em idade fértil e, em particular, as grávidas, para reduzir o risco de contaminação, além do monitoramento de gestantes que já tinham sido expostas ao ZIKV. Outras medidas em longo prazo também foram pactuadas, como pesquisas sobre a vacina contra o ZIKV, tratamento e meios de diagnóstico, além da sinalização da importância de os serviços de saúde estarem preparados para receber novas demandas de casos de síndromes neurológicas ou malformações congênitas 1 .

Nessa perspectiva, começou a corrida desenfreada dos cientistas e profissionais da saúde em busca de informações que pudessem contribuir para lidar com essa situação de saúde pública internacional. Outro ponto ressaltado era a preocupação com a proximidade dos Jogos Olímpicos e Paralímpicos, realizados na cidade do Rio de Janeiro em 2016, ou seja, a preocupação de que o ZIKV fosse disseminado mais rapidamente, antes de maiores informações que pudessem impedir o surto global.

Os surtos que ocorreram na Polinésia Francesa em 2013 e em outros momentos na África e na Ásia não apresentaram nenhuma notificação sobre doença grave 2. Já a epidemia que ocorreu no Brasil acarretou notificações. Logo, foram interligados ao ZIKV danos até então desconhecidos, com graves consequências, como a microcefalia ou alterações sugestivas de infecção congênita causadas por tal vírus.

Nesse contexto, a OMS definiu alguns critérios para identificar a microcefalia: recém-nascidos com um perímetro cefálico inferior a 2 desvios padrão, ou seja, mais de 2 desvios padrão abaixo da média para a idade gestacional e o sexo; e recém-nascidos com um perímetro cefálico inferior a 3 desvios padrão, ou seja, mais de 3 desvios padrão abaixo da média para a idade gestacional e o sexo, este último configurado como microcefalia grave 1. A principal forma de contaminação pelo ZIKV, associada à microcefalia, é a transmissão por meio da picada do mosquito Aedes aegypti infectado, embora haja também a contaminação sexual 3.

É necessário compreender, ainda, que os eventos relacionados ao ZIKV ocorreram em cenários com profundas desigualdades sociais: a infecção atingiu principalmente regiões pobres. Assim, a emergência da epidemia provocada pelo ZIKV entre pessoas que apresentam a marca histórica da falta de acesso a recursos para o diagnóstico e cuidados em saúde constitui uma preocupação ética 4 , além de política.

É imprescindível realizar uma reflexão sobre os interesses considerados públicos no campo da saúde. Há dificuldades de implementação de políticas que alcancem os direitos instituídos no marco da reforma sanitária. Ademais, as políticas públicas de enfrentamento à pobreza são subfinanciadas com per capitas anuais entre os mais baixos do mundo 5 .

Este artigo parte, portanto, do surto causado pelo ZIKV em 2015, que se tornou uma emergência nacional e internacional, após ser associado com a microcefalia em recém-nascidos. Teve como intuito compreender, para além de uma perspectiva organicista, a realidade vivenciada pelas mulheres infectadas e as consequências psicossociais geradas pela epidemia, para, então, alcançar os interesses delas e contribuir para o planejamento de políticas públicas que visem à igualdade de gênero. 


\section{Metodologia}

\section{A trajetória da pesquisa}

Para o alcance dos resultados foi feito um estudo etnográfico 6,7,8,9, mediante observação participante e realização de entrevistas, em uma instituição de referência no atendimento à saúde da mulher e da criança no Estado do Pará, Brasil. De julho a dezembro de 2018, pretendeu-se compreender as vivências de mulheres sobre a infecção do ZIKV na sala de espera do ambulatório da referida instituição.

Compartilham desse espaço mulheres com histórias particulares, mas que buscam um mesmo objetivo: o tratamento para o prognóstico de uma vida com qualidade para os filhos. A sororidade constante nos corredores do hospital começa antes do nascimento das crianças e persiste após o parto. Sentimentos de culpa, angústia e preocupação estão presentes nos diálogos. Em meio aos obstáculos enfrentados, surgem também sentimentos de esperança e alegria em cada conquista que elas dividem entre si. Assim, são criados laços entre elas, visibilizados pelo compartilhamento de vivências, da indagação sobre os tratamentos e dos desafios das lutas diárias, assim como de perdas.

Participaram deste estudo seis mães com filhos diagnosticados com microcefalia em função do ZIKV, número considerado equivalente à totalidade das mulheres nesta situação atendidas na referida instituição. Essas mulheres advinham dos seguintes municípios: Ananindeua, Abaetetuba, Barcarena, Belém, Garrafão do Norte e Moju. Com idades entre 17 e 32 anos, a maioria era casada ou vivia em união estável. Apenas uma declarou ser solteira. A renda mensal per capita das interlocutoras era inferior a 1 salário mínimo, sendo a Bolsa Família a única renda fixa de quatro delas. Com relação à escolaridade, duas possuíam o Ensino Fundamental incompleto; uma, o Ensino Fundamental completo; e três, o Ensino Médio completo. Das seis mulheres que participaram da pesquisa, uma se autodeclarava negra; quatro, pardas; e uma, branca (Quadro 1).

A imersão no campo possibilitou a compreensão da luta e da resistência dessas mulheres. As entrevistas, após transcritas, tiveram trechos considerados significativos organizados em "núcleos de sentido" 10, que foram discutidos entre as pesquisadoras e dispostos nos tópicos apresentados neste trabalho.

Como parte das reflexões éticas, para resguardar a identidade das interlocutoras da pesquisa, pseudônimos foram usados. Outras diretrizes, constantes das Resoluções no 466/2012 e no 510/2016, foram igualmente seguidas 11,12 . O projeto de pesquisa foi aprovado pelo Sistema CEP/Conep (CAAE 90519018.4.0000.0018 e 90519018.4.3001.5171).

\section{Quadro 1}

Perfil das interlocutoras da pesquisa.

\begin{tabular}{|c|c|c|c|c|c|c|}
\hline Nome & Rosângela & Maria & Joyce & Rita & Marlene & Lene \\
\hline Município & Ananindeua & Abaetetuba & Barcarena & Belém & $\begin{array}{c}\text { Garrafão do } \\
\text { Norte }\end{array}$ & Moju \\
\hline Idade & 30 anos & 17 anos & 24 anos & 28 anos & 27 anos & 32 anos \\
\hline Escolaridade & $\begin{array}{l}\text { Ensino Médio } \\
\text { completo }\end{array}$ & $\begin{array}{l}\text { Ensino } \\
\text { Fundamental } \\
\text { incompleto }\end{array}$ & $\begin{array}{l}\text { Ensino Médio } \\
\text { completo }\end{array}$ & $\begin{array}{l}\text { Ensino Médio } \\
\text { completo }\end{array}$ & $\begin{array}{c}\text { Ensino } \\
\text { Fundamental } \\
\text { incompleto }\end{array}$ & $\begin{array}{c}\text { Ensino } \\
\text { Fundamental } \\
\text { completo }\end{array}$ \\
\hline Estado civil & Solteira & $\begin{array}{c}\text { Convivente em } \\
\text { união estável }\end{array}$ & $\begin{array}{c}\text { Convivente em } \\
\text { união estável }\end{array}$ & Casada & Casada & Casada \\
\hline Renda & $\begin{array}{c}\text { Inferior a } \\
1 \text { salário mínimo }\end{array}$ & $\begin{array}{c}\text { Inferior a } \\
1 \text { salário mínimo }\end{array}$ & $\begin{array}{c}\text { Inferior a } \\
1 \text { salário mínimo }\end{array}$ & $\begin{array}{c}\text { Inferior a } \\
1 \text { salário mínimo }\end{array}$ & $\begin{array}{c}\text { Inferior a } \\
1 \text { salário mínimo }\end{array}$ & $\begin{array}{c}\text { Inferior a } \\
1 \text { salário mínimo }\end{array}$ \\
\hline Raça & Parda & Branca & Negra & Parda & Parda & Parda \\
\hline Religião & Evangélica & Católica & Sem religião & Católica & Evangélica & Católica \\
\hline
\end{tabular}




\section{Resultados e discussão}

\section{A gestação, o diagnóstico e o aborto como possibilidade}

O surto causado pelo ZIKV gerou consequências não somente físicas como também emocionais para todos os envolvidos. Entretanto, há um grupo particular que tem de lidar todos os dias com as dificuldades dessa nova realidade imposta: as mulheres.

Aliás, a gravidez, por si só, é um momento que traz grandes mudanças no seio da família, principalmente da genitora. A gestação, o parto e o puerpério são etapas da vida reprodutiva consideradas fisiológicas, que necessitam, contudo, de uma atenção especial por parte da família e dos profissionais da saúde, exatamente porque podem acarretar um comprometimento da saúde mental das mulheres. Especificamente após o parto, situações de vulnerabilidade, caracterizadas por tristeza, ansiedade, fadiga, diminuição da concentração, irritabilidade e insônia, podem afetar as mães e suas relações familiares e sociais 13 .

Há, portanto, mudanças fisiológicas e, ainda, psicológicas e sociais no período gestacional, no parto e no puerpério. Quando do diagnóstico confirmado da síndrome congênita do ZIKV, além dos sentimentos que todas as grávidas estão propícias a sentir, outros permeiam a futura mãe. As responsabilidades pelo cuidado integral, a desigualdade de gênero ainda presente na sociedade e o afastamento do mercado de trabalho são algumas das situações que podem contribuir para o comprometimento da saúde mental da mulher, especialmente se ela não estiver apoiada por uma rede de assistência.

Assim, em tempo de epidemia do ZIKV, há o medo da descoberta, ao longo das consultas do prénatal, de algo fora do esperado sobre a saúde da criança 14. Para algumas mulheres, a gestação pode ser uma boa notícia; para outras, um motivo de preocupação.

"Eu viajei para o interior do estado, conheci um rapaz que tive um relacionamento no perído que estava lá. Quando retornei para Belém, descobri a gravidez. No entanto, trabalhava como diarista em uma loja e já tenho uma filha. A descoberta da gravidez foi um susto muito grande por causa da questão financeira. Foi, então, que meu irmão falou que adotava a criança quando nascesse, porque já não tinha condições nem para minha outra filha de seis anos" (Rosângela, Diário de Campo, 2018; grifo nosso).

Ao continuar narrando sua história, Rosângela contou que aos três meses de gestação descobriu algo "errado". Entretanto, não teve muita informação no pré-natal sobre deficiência.

"Lembro-me que a médica disse que a criança provavelmente teria uma deficiência na cabeça, mas foi só isso. Não me deu outras informações. Então, como tinha conhecido uma criança com hidrocefalia, achei que podia ser isso. Me desesperei e chorei muito, pensei em até abortar, mas não tive coragem. Meu irmão desistiu de adotar a criança, falou que me ajudaria, mas não podia ficar com a criança doente. Era muito trabalho" (Rosângela, Diário de Campo, 2018).

A rejeição familiar é um dos primeiros obstáculos que aparecem para mulheres como Rosângela. Contudo, o maior empecilho é a própria culpabilização por não aceitarem a gestação de uma criança com limitações. Os sentimentos oscilam entre amor e ódio, aceitação e rejeição 15,16,17.

Diante do diagnóstico, algumas mulheres afirmaram que passaram por diversos exames cujos resultados nem sempre eram claros e definitivos. Muitas dúvidas as cercaram por toda a gravidez. "Tive que aprender a lidar com todas as vozes questionadoras na minha cabeça" (Rosângela, Diário de Campo, 2018).

O modo como os profissionais da saúde pronunciam um diagnóstico pode causar mais (ou menos) dor a essas mulheres e seus familiares 17,18. Informações sobre as limitações da criança e mesmo a possibilidade de morte são dadas. Essa aproximação acaba sendo feita muitas vezes de forma desumanizada, sem preocupação com um acolhimento adequado 18 .

"Me emociono só de lembrar. Quando fui fazer a ultrassonografia morfológica, estava sozinha. Então, o médico ficou mudo por alguns minutos. Fiquei logo apreensiva (...). Então, me disse que teria uma criança especial, que precisava procurar um especialista e ponto! Senti a frieza naquela frase. Pronto! Pensei longo em sindrome de Down, mas depois ele me falou da cabecinha. Pesquisei muito em casa. Chorei quase por uma semana remoendo cada palavra daquele dia" (Lene, Diário de Campo, 2018).

"No dia que soube, vi o meu mundo desabar na minha cabeça! Gente, é horrivel saber uma coisa dessa. Hoje é diferente. Eu amo minha filha do jeitinho que é, mas foi difícil isso, foi" (Joyce, Diário de Campo, 2018). 
Deve-se considerar, portanto, uma atenção humanizada desde o diagnóstico 16. Aliás, diante das incertezas científicas e da impossibilidade de interromper a gestação, algumas mulheres preferem não realizar o pré-natal se apresentam sinais de infecção pelo ZIKV. Recusam-se a fazer ultrassonografia como forma de resistência ou negação do diagnóstico precoce, que se torna uma tortura psicológica 19.

"Sempre tive medo de ter uma criança com problemas. Então, nunca tive muito acesso às informações $e$ nada disso. Lembro que me deram um repelente no posto de saúde, mas nem explicaram a importância. Sei lá! Tinha medo de ouvir que algo estava errado. Foi, então, que fui fazer aquele exame [ultrassonografia]. Logo questionei o doutor se estava tudo bem mesmo. Ele olhou e me disse que aparentemente sim, mas que o bebê poderia nascer com a cabeça pequena. Não entendi. Só fui entender depois que nasceu mesmo" (Lene, Diário de Campo, 2018).

A gestação de uma criança é cercada por várias expectativas, como o desejo de que ela seja saudável. Nesses casos, os pais devem lidar, então, com sentimentos de frustração, medo e até mesmo rejeição como parte do processo de enfrentamento da deficiência apresentada pela criança 20.

Apesar de não ser o caso de nenhuma interlocutora, esses sentimentos, entre outros motivos, podem remeter, ainda, à busca pela realização de um aborto ilegal e inseguro. Como os dados científicos sobre as consequências da infecção são muito incipientes, o futuro para essas mulheres é desconhecido. Nem a própria ciência fornece informações precisas para que elas possam exercer uma maternidade consciente dos danos e agravos que podem surgir em decorrência do ZIKV. Assim, a possibilidade de aborto legal e seguro para esses casos não deve ser compreendida como uma forma de eugenia, mas como um livre exercício dos direitos reprodutivos, além de se considerar a saúde mental dessas mulheres que estão em sofrimento psíquico 21.

Na pesquisa, mencionar o aborto como possibilidade para as mulheres que se tornaram mães foi uma situação delicada. Como indagar sobre o desejo de ter interrompido a gestação de alguém que já nasceu? A oportunidade de abordar o assunto ocorreu por meio de uma reportagem que passava na televisão no ambulatório. Na ocasião, os pais de Gabriel afirmaram em coro que eram contra "esse negócio de tirar a criança", porque viam esta opção como uma agressão à vontade de Deus. A oposição ao aborto pode estar relacionada à religiosidade desse casal. Das seis mulheres que participaram da pesquisa, três declararam ser católicas; duas, evangélicas; e uma declarou apenas acreditar em Deus, não mencionando nenhuma religião. A Pesquisa Nacional do Aborto (PNA) indica, contudo, que a religião não é um fator importante para a diferenciação das mulheres em relação à realização do aborto, dado que reflete a composição religiosa do país: a maioria dos abortos foi feita por católicas, seguidas de protestantes e evangélicas e, finalmente, por mulheres de outras religiões ou sem religião 22 .

Em outra oportunidade o tema foi abordado com outras duas mulheres, que mantiveram o posicionamento dos pais de Gabriel, apesar de uma ter dito que pensou nessa possibilidade no início, porém não teve coragem de levá-la a cabo.

Algumas mães de crianças com deficiência parecem não se alinhar a uma das agendas do feminismo no tocante a questões como o aborto 23. Entretanto, é importante destacar que a luta do movimento feminista é em prol do direito de liberdade de escolha, podendo a mulher optar por dar ou não prosseguimento a uma gravidez.

Nesse contexto, é necessário analisar o Protocolo de Vigilância e Resposta à Ocorrência de Microcefalia e/ou Alterações do Sistema Nervoso Central (SNC), do Ministério da Saúde 24. Há diversas lacunas que permeiam o referido documento no que tange ao contexto social no qual o ZIKV emerge. Ao se definir a importância do acesso à informação e aos serviços de saúde, esse Protocolo ignora os desafios enfrentados por mulheres pobres, negras e pardas que vivem nas áreas mais afetadas pela epidemia. Além disso, omite dados concernentes ao aborto, que, apesar de ser uma prática considerada como crime, é realizado, de forma insegura, no país 25 . Aos 40 anos, quase uma em cada cinco mulheres brasileiras já fez um aborto; somente no ano de 2015, ocorreram cerca de meio milhão de abortos. Esses dados mostram que o aborto é um problema de saúde pública 22.

Destarte, diante dos agravos com a infecção pelo ZIKV, o Protocolo deixa de contemplar políticas públicas que deveriam atentar para diversos problemas sociais. O Estado torna-se, assim, negligente ao não tomar medidas claras e efetivas para o enfrentamento do problema, que aprofunda cada vez mais as diferenças sociais existentes. 


\section{Os corredores como espaços de resistência das mulheres}

Os corredores da instituição pesquisada constituem espaços de interação entre as mães, que neles dividem suas experiências e criam resistência para lutar pelos direitos de seus filhos.

Foi perceptível no período da etnografia que as mulheres que exercem o papel de cuidadoras não possuem apoio referente à saúde mental. Ao verificar os prontuários disponíveis de quatro mulheres que deram entrada na instituição com crianças com diagnóstico de microcefalia no período do puerpério, não foi encontrado nenhum registro de atendimento psicossocial para atender às demandas delas.

Por algumas vezes foi observado o mesmo fato sobre as demandas de cunho social, pois algumas mulheres - principalmente as advindas do interior do estado - mostravam-se desorientadas sobre os seus direitos, relatavam que "ouviram falar" que poderiam receber uma "aposentadoria", mas não sabiam exatamente o que era.

Tampouco foram planejados pela instituição espaços nos quais essas mulheres pudessem compartilhar suas dificuldades, medos e experiências com os profissionais. Os únicos espaços destinados a elas são as salas de espera para aguardar as consultas. Nos corredores e em conversas no WhatsApp suas vozes e vivências são validadas.

Os relatos retratam que suas vidas foram radicalmente modificadas, uma vez que tiveram de abandonar sonhos em prol da criança que necessita de acompanhamento. Para os serviços da rede, entretanto, tornam-se invisíveis. Dificilmente conseguem ser ouvidas; suas falas não são consideradas como importantes 26 .

"A fala do usuário é somente requerida em termos minimalistas" 27 (p. 10). Essas mulheres são tidas apenas como receptoras de informações que nem mesmo a ciência sabe explicar com exatidão.

"É sempre possível pensar que os efeitos da fala autoritária médica, da imposição de barreiras invisíveis (até no tom de voz que marca a distância) e da posição superior na hierarquia de valores sociais e de saberes, tenham a eficácia de produzir a autodesqualificação dos usuários no âmbito do espaço hospitalar" 27 (p. 14).

Essa barreira invisível é instalada por meio do poder simbólico do jaleco, da caneta e, principalmente, da hierarquia estabelecida entre profissional da saúde e usuário, e prejudica quem necessita de um olhar e uma escuta não autoritários e preconcebidos de valores morais 14 .

As mulheres buscam uma perspectiva que abarque a saúde numa concepção integral. Nesse sentido, a Política Nacional de Humanização (PNH) "busca transformar as relações de trabalho a partir da ampliação do grau de contato e da comunicação entre as pessoas e grupos, tirando-os do isolamento e das relações de poder hierarquizadas" 28 (p. 6).

Apesar de essa política estabelecer o protagonismo do usuário, tendo como objetivo "a construção de relações de confiança, compromisso e vínculo entre as equipes/serviços, trabalhador/equipes e usuário com sua rede socioafetiva" 28 (p. 8), essas relações, de acordo com os relatos obtidos, são frágeis e subestimam a capacidade das mulheres de participar dos processos de decisões.

Essa situação remete às medidas de isolamento das pessoas com diagnóstico de hanseníase, que eram pautadas na exclusão como justificativa de controle do contágio. Essas medidas, embora tenham sido adotadas pelo estado sob a justificativa de exercício da "saúde pública”, contribuíram para a discriminação que as afetaria por toda a vida, isolando-as permanentemente do convívio social 29.

Assim, também as mães das crianças com microcefalia que engravidaram no período considerado pelo Estado como "inapropriado" para uma gravidez sofreram (e sofrem ainda) frequente discriminação e são responsabilizadas pela doença. A transferência da responsabilidade é repassada a essas mulheres, que escutam dos profissionais da saúde comentários como: "Você não sabia do surto? Por que engravidou?", “Não usou repelente e roupas?" e "Não viu as reportagens?”. Esses profissionais buscam culpabilizá-las por não terem condições socioeconômicas favoráveis e ainda terem engravidado, mesmo quando o estado "ordenou" que não era o melhor período.

Nesse contexto, emerge um estado paternalista que orientou, porém não foi ouvido, mas que "ajudará" as mães que foram afetadas por meio de auxílios, como o Benefício de Prestação Continuada (BPC). A desresponsabilização do estado soma-se, portanto, à culpabilização das mulheres e à consequente ausência dele em propor políticas públicas mais efetivas que forneçam condições de vida e saúde para essa população. Essas mulheres são violadas econômica, psicológica e socialmente. 
Os muros da segregação no caso da hanseníase nem sempre estiveram localizados em áreas geográficas bem definidas 29 . Nesta pesquisa, muitas mulheres sofrem igualmente com o isolamento social. É recorrente a referência às "perdas", seja de liberdade, do emprego, da rotina, da convivência com familiares ou, a principal, de si mesma. Em certa ocasião, Joyce relatou que nem se lembrava da última vez que conseguiu se olhar no espelho ou sair sozinha; já não se via como mulher, e sim como a mãe da criança que precisa de muitos cuidados.

A exclusão e a discriminação a que essas mulheres são submetidas remetem à "mortificação do eu" goffmaniana 30, não em instituições totais, mas em instituições sociais, uma vez que essas mulheres perdem suas identidades para cuidar apenas do outro; carregam a função que foi socialmente estabelecida de serem cuidadoras. Essa situação se agrava, passados quatro anos do surto do ZIKV, quando elas, além de terem sido excluídas, vivenciam hodiernamente o esquecimento.

\section{Redes de apoio e cuidados}

A família também sofre com a realidade cotidiana do cuidado da criança por meio de uma rotina intensa. Esse papel carece de ser compartilhado com os serviços de saúde. O suporte direcionado às mães e demais familiares de crianças com microcefalia deve ocorrer como proteção e promoção da saúde mental para todos os envolvidos 31 .

O cuidado centrado na família (CCF) enfatiza o reconhecimento da participação da família em todas as ações e tomada de decisões. Essa abordagem ressalta a necessidade de conscientização da equipe e articulação dos serviços de saúde com os familiares desde o diagnóstico. A incumbência dos profissionais da saúde não é uma ajuda, mas sim um dever, que possibilita à família tornar-se preparada para lidar com situações nunca antes vivenciadas 32 .

Nessa perspectiva, a família que toma conhecimento de alguma deficiência e tem suas expectativas de um bebê idealizado confrontadas com o bebê real deve ser acolhida em seus medos, dúvidas e necessidades, com apoio para que possa enfrentar a realidade imposta no ato de cuidar 33. "A família da criança deficiente vivencia uma sobrecarga adicional em todos os níveis: social, psicológico, financeiro e com relação à demanda de cuidados e reabilitação da criança, necessitando por isso acessar as redes de suporte social disponiveis na comunidade" 32 (p. 197).

Em relação à sobrecarga que recai sobre as cuidadoras, Joyce mencionou os desgastes que afetavam suas relações com os membros da sua família, pois no decorrer da semana tem uma agenda comprometida com a filha caçula que, além de realizar consultas ambulatoriais, também faz acompanhamento no Núcleo Ampliado de Saúde da Família e Atenção Básica (NASF). Devido a esses compromissos, os outros filhos acabam ficando muito tempo sozinhos. Na semana anterior a uma de nossas conversas, havia procurado uma Unidade de Pronto Atendimento (UPA) com fortes dores na coluna, sendo medicada e liberada, muito embora as dores tivessem permanecido.

Essas mulheres exercem inúmeras atividades, como consultas, reabilitação e marcação de exames, embora nem todas tenham acesso a todos os serviços devido à indisponibilidade deles nos municípios dos quais são oriundas, como é o caso de Marlene, mãe de Gabriel, que faz o acompanhamento do filho no máximo uma vez ao mês ou a cada dois meses. Como mora na zona rural, Marlene afirmou que o filho nunca tinha passado por uma sessão de reabilitação. Além disso, a unidade de saúde mais próxima de sua casa não tem estrutura adequada, mas já tinha ouvido falar da existência de um NASF, localizado, contudo, longe de sua residência, na área urbana.

Também Marlene viu a vida mudar, pois trabalhava na roça com o marido e teve de parar para se dedicar ao cuidado do filho. "Não tinha ninguém que pudesse ficar com a criança. Todos os parentes saem cedo" (Marlene, Diário de Campo, 2018). Ela contou que nos dias das consultas na capital, além de a viagem ser muito desgastante, fica muito preocupada com os outros filhos, que ficam sozinhos em sua casa porque o marido a acompanha. Ainda não recebe o BPC porque "tem muita papelada; é difícil conseguir tudo" (Marlene, Diário de Campo, 2018), o que dificulta a situação da família, já que a única renda fixa é a Bolsa Família.

Segundo Lene (Diário de Campo, 2018), "Mudou muito depois que ele nasceu. Nem todos que moram na minha casa tiveram que aprender a lidar com a realidade. Infelizmente, nem todos conseguem, né?! Eu mesma fico triste porque tenho que engolir muitos 'sapos' de alguns familiares. Sabe, tem gente que olha como se ele fosse um 'monstro' e não é, só não se permite conviver com a diferença". 
Em uma ocasião, a ex-sogra de Rosângela, que a acompanhava, assim discorreu sobre a neta: "Eles moram atrás de casa. Já tenho outros netos. Todos são normais. Quando a menina nasceu, eu confesso que fiquei triste porque até então não entedia muita coisa sobre a doença. Logo me acostumei. Hoje não tem um dia que não dou um cheiro nela, mas não tenho coragem de ficar com ela sozinha. Tenho medo de acontecer algo. Sabe, é diferente dos outros bebês. Deus me livre de ela passar mal e morrer nos meus braços" (avó de Eduarda, Diário de Campo, 2018).

A família é entendida como uma unidade social permeada por relações complexas. Por conseguinte, toda mudança que ocorre com um membro dela afeta as relações já existentes 15,17. A busca pela convivência com a diferença, requerida por Lene em sua fala, remete à necessidade de criação, a partir dessa nova realidade, tanto de uma rede de apoio familiar quanto de uma rede mais ampla sustentada por serviços disponibilizados pelo estado.

As redes formais de serviços no Estado do Pará não foram preparadas para atuar diante da realidade imposta pelo ZIKV. As medidas tomadas pelo poder público não ultrapassaram os atendimentos pontuais na assistência à saúde, sendo eles realizados predominantemente para atender às demandas das crianças. Não foi identificado nenhum serviço que acolhia as demandas das mães, como Centros de Atenção Psicossocial (CAPS), que poderiam ser capacitados para receber essas mulheres e fornecer a elas serviços de atenção à saúde mental.

Ademais, as interlocutoras da pesquisa relataram que somente conseguiram acessar a rede formal de atendimento especializado depois de um processo longo e burocrático. Diante da emergência em saúde pública ocorreu a necessidade de reorganização dos serviços, sem, contudo, planejamento e organização do fluxo 34.

No Estado do Pará, houve, em 2018, 21 casos confirmados de recém-nascidos e crianças vivas com alterações no crescimento e desenvolvimento, possivelmente relacionadas à infecção pelo ZIKV e outras etiologias infecciosas. As notificações apontam que apenas cinco atendimentos em puericultura e estimulação precoce foram feitos, ou seja, $76,2 \%$ dos casos confirmados não estão inseridos nos atendimentos citados 35 .

Além disso, analisou-se que não há uma especificidade nos atendimentos em comparação a outras deficiências. Ao contrário de outros diagnósticos de deficiência presentes na infância, não há ainda muitas informações sobre o prognóstico das crianças afetadas pelo ZIKV. Nesse sentido, percebemse o medo e a insegurança das mães por falta de informações e orientações que realmente supram as dúvidas constantes.

Assim, atribui-se à rede o desafio da intersetorialidade como finalidade de articular as políticas e os programas, como a Política Nacional de Saúde Integral da População Negra 36, que tem como marca o "reconhecimento do racismo, das desigualdades étnico-raciais e do racismo institucional como determinantes sociais das condições de saúde, com vistas à promoção da equidade em saúde"; a Política Nacional de Atenção Integral à Saúde da Mulher 37, que, norteada pela "perspectiva de gênero, de raça e de etnia" (p. 63), visa a "qualificar a atenção à saúde mental das mulheres" (p. 71); e a Rede Cegonha 38, que retrata a "rede de cuidados que visa assegurar à mulher o direito ao planejamento reprodutivo e à atenção humanizada à gravidez, ao parto e ao puerpério". Todas essas políticas fortalecem os princípios e as diretrizes do Sistema Único de Saúde (SUS), segundo os quais a saúde é um direito de todos os cidadãos, entre os quais as mulheres, e dever do Estado 39.

\section{Considerações finais}

Diante desses achados, ressalta-se que no Estado do Pará não houve uma grande incidência da microcefalia causada pelo ZIKV, como na Região Nordeste, especificamente no Estado de Pernambuco. Esse número reduzido não significa, contudo, que deve haver um esquecimento dessa população. Mesmo poucas, as mulheres cujos filhos foram diagnosticados com microcefalia necessitam de tratamento, não apenas restrito aos filhos, mas especialmente de uma atenção humanizada em prol da saúde no conceito ampliado. Justamente por não haver um grande número de casos, essas mulheres acabam passando despercebidas pelo poder público, não havendo uma rede que dê atenção direcionada para elas. Ademais, a desassistência verificada nesse estado pode ser um indício de que tantas outras mulheres, de outros estados, podem ter sido igualmente esquecidas pós-surto do ZIKV. 
Deve-se compreender que a saúde da mulher envolve, além das questões físicas, as emocionais, principalmente após o nascimento de uma criança com deficiência. As mulheres nessa situação não foram ouvidas ou cuidadas, além do atendimento normatizado para um pós-parto; ao contrário, foram culpabilizadas por terem engravidado mesmo não tendo condições consideradas "necessárias" para se ter um filho e, então, responsabilizadas pelo cuidado.

A saúde mental dessas mulheres é afetada desde o início da gravidez. Logo, os contextos familiar e social tornam-se importantes para fomentar discussões sobre as práticas de saúde e as representações que o ZIKV acarreta para as mulheres que tiveram sua vida alterada pela situação que provocou um grande alarme em toda a sociedade.

As mulheres carregam historicamente o papel de cuidadoras. Esse papel pode se tornar um "gatilho" para diversas doenças, físicas e mentais, pois os desafios com as consequências do ZIKV são constantes e requerem delas mudanças significativas. No entanto, aquelas que participaram desta pesquisa alegaram não haver um acompanhamento adequado. Referiram-se apenas a encaminhamentos para a busca de benefícios sociais e cuidado para as crianças. Verifica-se, assim, que embora a saúde mental dessas mulheres seja afetada, os contextos familiar, social e de atenção à saúde não as amparam.

É necessário compreender que os determinantes sociais que envolvem os prognósticos das crianças devem considerar a família. Ela deve ser compreendida como o elo principal no tratamento da criança. Entretanto, ainda é percebida como receptora de informações, ficando as atenções centralizadas na patologia.

A "maternidade militante" 33 , descoberta nos corredores da instituição pesquisada, modifica essa relação de poder entre profissionais da saúde e usuários ao mostrar a busca de mulheres pelos direitos de seus filhos - pela garantia de uma política de vida para as crianças com microcefalia. Essas mulheres empoderam-se por meio das lutas diárias e ocupam o lugar de agentes políticos que buscam o direito de viver.

Conclui-se, assim, que não somente as propostas políticas precisam ser revisitadas com enfoque nessa nova realidade imposta, sobretudo para resguardar a integridade física e emocional das mulheres, como também a efetivação delas deve ser garantida, com o intuito de traçar melhorias na atenção aos direitos reprodutivos e à saúde mental dessas mulheres.

\section{Colaboradores}

D. A. Silva contribuiu substancialmente na concepção e desenho do trabalho, na aquisição, análise e interpretação de dados e na redação do artigo. E. Quinaglia Silva colaborou substancialmente na concepção e desenho do trabalho, revisão crítica do conteúdo intelectual e aprovação final da versão a ser publicada.

\section{Informações adicionais}

ORCID: Deisiane Amorim da Silva (0000-00016773-973X); Érica Quinaglia Silva (0000-00019526-7522).

\section{Agradecimentos}

Agradecemos à Coordenação de Aperfeiçoamento de Pessoal de Nível Superior (CAPES) pelo fornecimento da bolsa de mestrado à D. A. Silva e ao Conselho Nacional de Desenvolvimento Científico e Tecnológico (CNPq) pela concessão da bolsa de produtividade em pesquisa à E. Quinaglia Silva, financiamentos que possibilitaram a realização desta pesquisa. 


\section{Referências}

1. Organização Pan-Americana da Saúde. Declaração da OMS: 3a reunião do Comitê de Emergência sobre vírus Zika e aumento observado em distúrbios neurológicos e malformações neonatais. https://www.paho.org/bra/ index.php?option $=$ com_content \&view $=$ arti cle\&id = 5153: declaracao-da-oms-3a-reuniaodo-comite-de-emergencia-sobre-virus-zika-e -aumento-observado-em-disturbios-neurolo gicos-e-malformacoes-neonatais $\&$ Itemid $=812$ (acessado em Mai/2019).

2. Ioos S, Mallet HP, Leparc Goffart I, Gauthier V, Cardoso T, Herida M. Current Zika virus epidemiology and recent epidemics. Med Mal Infect 2014; 44:302-7.

3. Oliveira RL, Failloux AB. Lessons learned on Zika virus vectors. PLoS Negl Trop Dis 2017; 11:e0005511.

4. Rego S, Palácios M. Ética, saúde global e a infecção pelo vírus Zika: uma visão a partir do Brasil. Rev Bioét 2016; 24:430-4.

5. Santos NR. A reforma sanitária e o Sistema Único de Saúde: tendências e desafios após 20 anos. Saúde Debate 2009; 33:13-26.

6. Malinowski BK. Argonautas do Pacífico Ocidental. 2a Ed. São Paulo: Abril Cultural; 1978.

7. Oliveira RC. O trabalho do antropólogo. 2a Ed. São Paulo: Editora da UNESP; 2000.

8. Peirano M. Etnografia, ou a teoria vivida. Ponto Urbe 2008; 2(2). https://journals.openedi tion.org/pontourbe/1890.

9. Peirano M. Etnografia não é método. Horizontes Antropológicos 2014; 20:377-91.

10. Minayo MCS. O desafio do conhecimento: pesquisa qualitativa em saúde. 9a Ed. São Paulo: Editora Hucitec; 2006.

11. Conselho Nacional de Saúde. Resolução no 466, de 12 de dezembro de 2012. Dispõe sobre diretrizes e normas regulamentadoras de pesquisas envolvendo seres humanos. Diário Oficial da União 2013; 13 jun.

12. Conselho Nacional de Saúde. Resolução no 510, de 7 de abril de 2016. Dispõe sobre as normas aplicáveis a pesquisas em Ciências Humanas e Sociais. Diário Oficial da União 2016; 24 mai.

13. Carvalho GM, Oliveira LR, Santos RV, Camiá GEK, Soares LH. Transtornos mentais em puérperas: análise da produção de conhecimento nos últimos anos. Brazilian Journal of Health Review 2019; 2:3541-58.

14. Carneiro R, Fleischer SR. "Eu não esperava por isso. Foi um susto”: conceber, gestar e parir em tempos de Zika à luz das mulheres de Recife - PE, Brasil. Interface (Botucatu) 2018; 22:709-19.

15. Ferrari JP, Morete MC. Reações dos pais diante do diagnóstico de paralisia cerebral em crianças com até 4 anos. Cadernos de Pós-Graduação em Distúrbios do Desenvolvimento 2004; 4:25-34.

16. Lara EB, Pinos CC. Families with a disabled member: impact and family education. Procedia Soc Behav Sci 2017; 237:418-25.
17. Vale PRLF. Experiências de famílias de crianças com microcefalia por Zika vírus [Dissertação de Mestrado]. Feira de Santana: Universidade Estadual de Feira de Santana; 2018.

18. Costa ES, Bonfim EG, Magalhães RLB, Viana LMM. Vivências de mães de filhos com microcefalia. Rev RENE 2018; 19:e3453.

19. Diniz D. Vírus Zika e mulheres. Cad Saúde Pública 2016; 32:e00046316.

20. Martin MAF, Teixeira MCTV, Carreiro LRR. Orientações para promoção de saúde mental e qualidade de vida em pais e seus filhos com síndrome de Williams. São Paulo: Memnon; 2014.

21. Prata ARS, Pedroso D, Menezes G, Drezett J, Torres JH, Bonfim JRA, et al. Documento sobre Zika vírus e interrupção da gravidez. Rio de Janeiro: Grupo de Estudos sobre Aborto; 2017.

22. Diniz D, Medeiros M, Madeiro A. Pesquisa Nacional de Aborto 2016. Ciênc Saúde Colet 2017; 22:653-60.

23. Scott RP, Quadros MT, Rodrigues AC, Lira LC, Matos SS, Meira F, et al. A epidemia de Zika e as articulações das mães num campo tensionado entre feminismo, deficiência e cuidados. Cadernos de Gênero e Diversidade 2017; 3:73-92.

24. Departamento de Vigilância das Doenças Transmissíveis, Secretaria de Vigilância em Saúde, Ministério da Saúde. Protocolo de vigilância e resposta à ocorrência de microcefalia e/ou alterações do sistema nervoso central (SNC). Brasília: Ministério da Saúde; 2015.

25. Baum P, Fiastro A, Kunselman S, Vega C, Ricardo C, Galli B, et al. Garantindo uma resposta do setor de saúde com foco nos direitos das mulheres afetadas pelo vírus Zika. Cad Saúde Pública 2016; 32:e00064416.

26. Carvalho LDP. Da esterilização ao Zika: interseccionalidade e transnacionalismo nas políticas de saúde para as mulheres [Tese de Doutorado]. São Paulo: Universidade de São Paulo; 2017.

27. Machado LZ. Entre o inferno e o paraíso. Saúde, direitos e conflitualidades. Brasília: Universidade de Brasília; 2003. (Série Antropologia).

28. Ministério da Saúde. Política Nacional de Humanização (PNH): documento base para gestores e trabalhadores do SUS. Brasília: Ministério da Saúde; 2013.

29. Maricato G. Os muros do Estado: dos limites da política reparatória aos atingidos pela hanseníase. In: Maluf SW, Quinaglia Silva E, organizadores. Estado, políticas e agenciamentos sociais em saúde: etnografias comparadas. Florianópolis: Editora da UFSC; 2018. p. 145-66.

30. Goffman E. Manicômios, prisões e conventos. 8a Ed. São Paulo: Perspectiva; 2010.

31. Brunoni D, Blascovi-Assis SM, Osório AAC, Seabra AG. Amato CAH, Teixeira MCTV, et al. Microcefalia e outras manifestações relacionadas ao vírus Zika: impacto nas crianças, nas famílias e nas equipes de saúde. Ciênc Saúde Colet 2016; 21:3297-302. 
32. Barbosa MAM, Balieiro MMFG, Pettengill MAM. Cuidado centrado na família no contexto da criança com deficiência e sua família: uma análise reflexiva. Texto \& Contexto Enferm 2012; 21:194-9.

33. Pinheiro DAJP, Longhi MR. Maternidade como missão! A trajetória militante de uma mãe de bebê com microcefalia em PE. Cadernos de Gênero e Diversidade 2017; 3:113-33.

34. Mendes AG, Campos DS, Silva LB, Moreira MELM, Arruda LO. Enfrentando uma nova realidade a partir da síndrome congênita do vírus zika: a perspectiva das famílias. Ciênc Saúde Colet 2019; [Epub ahead of print].

35. Secretaria de Vigilância em Saúde, Ministério da Saúde. Monitoramento integrado de alterações no crescimento e desenvolvimento relacionadas à infecção pelo vírus Zika e outras etiologias infecciosas até a Semana Epidemiológica 45 de 2018. Boletim Epidemiológico 2018; 50(8).
36. Ministério da Saúde. Portaria no 992, de 13 de maio de 2009. Institui a Política Nacional de Saúde Integral da População Negra. Diário Oficial da União 2009; 14 mai.

37. Departamento de Ações Programáticas Estratégicas, Secretaria de Atenção à Saúde, Ministério da Saúde. Política nacional de atenção integral à saúde da mulher: princípios e diretrizes. Brasília: Ministério da Saúde; 2004.

38. Ministério da Saúde. Portaria no 1.459 , de 24 de junho de 2011. Institui, no âmbito do Sistema Único de Saúde, a Rede Cegonha. Diário Oficial da União 2011; 25 jun.

39. Brasil. Lei no 8.080 , de 19 de setembro de 1990. Dispõe sobre as condições para a promoção, proteção e recuperação da saúde, a organização e o funcionamento dos serviços correspondentes e dá outras providências. Diário Oficial da União 1990; 20 set. 


\section{Abstract}

The current study reflects on the Zika virus outbreak that struck the Brazilian population, with both physical and emotional aspects for all those affected. There is a particular group that has to deal on a daily basis with all the difficulties imposed by this new reality: women. The basic assumption of this approach is the need to learn about, understand, and grasp these biopsychosocial issues in all their breadth. It becomes necessary to delve into a relatively new context that mainly affected poor black and brown Brazilian women with little schooling in order to improve attention to their reproductive rights and mental health. The study thus accessed the reality of women who had children with a diagnosis of microcephaly due to the Zika virus. An ethnographic study performed with a qualitative approach in a referral service for women and children's health in Pará State. The study showed that women in this situation were not listened or cared for, except with routine postpartum care. This shortcoming notwithstanding, the mental health of these women is affected from the beginning of the pregnancy. Thus, the family and social contexts become important for promoting discussions on the health practices and representations that Zika entails for women who have had their lives altered by a situation that sounded a huge alarm throughout Brazilian society.

Zika Virus; Mental Health; Public Policy

\section{Resumen}

Este trabajo plantea una reflexión sobre el brote causado por el virus del Zika, que alcanzó a la población brasileña y acabó generando consecuencias, no solamente físicas, sino también emocionales para todos los implicados. Existe un grupo particular que tiene que lidiar todos los días con las dificultades que esta nueva realidad impone: las mujeres. El abordaje de este tema parte del presupuesto de la necesidad de conocer, comprender y aprender estas cuestiones biopsicosociales dentro de su amplitud y magnitud. Es necesario adentrarse en un contexto relativamente nuevo que afectó principalmente a mujeres negras y mestizas, pobres y con baja escolaridad, a fin de delinear mejoras en la atención a sus derechos reproductivos y su salud mental. Así, se tuvo acceso a la realidad de las mujeres que tuvieron hijos con un diagnóstico de microcefalia, debido al virus del Zika. Para tal fin, se realizó un estudio de abordaje cualitativo, de cuño etnográfico, en una institución de referencia en la atención de la salud de la mujer y del niño en el Estado de Pará. Se verificó que las mujeres en esta situación no fueron escuchadas o cuidadas, más allá de la atención estandarizada para un posparto. Se concluyó que, además de esta carencia en la atención, la salud mental de estas mujeres se ve afectada desde el principio del embarazo. Así pues, los contextos familiares y sociales se convirtieron en importantes áreas desde donde fomentar discusiones sobre las prácticas de salud $y$ las representaciones que el Zika acarrea para las mujeres que vieron su vida trastocada por una situación que provocó una gran alarma en toda la sociedad.

Virus Zika; Salud Mental; Politica Pública
Recebido em 27/Mai/2019

Versão final reapresentada em 16/Dez/2019

Aprovado em 29/Jan/2020 